\title{
Sunscreens - Which and What for?
}

\author{
T. Maier H.C. Korting \\ Department of Dermatology and Allergology, Ludwig Maximilian University, Munich, Germany
}

\author{
Key Words \\ Sunscreen - UV radiation - Oxybenzone - Zinc oxide • \\ Skin cancer, nonmelanoma $\cdot$ Nanoparticle • \\ Microcapsules, glass
}

\begin{abstract}
It is well established that sun exposure is the main cause for the development of skin cancer. Chronic continuous UV radiation is believed to induce malignant melanoma, whereas intermittent high-dose UV exposure contributes to the occurrence of actinic keratosis as precursor lesions of squamous cell carcinoma as well as basal cell carcinoma. Not only photocarcinogenesis but also the mechanisms of photoaging have recently become apparent. In this respect the use of sunscreens seemed to prove to be more and more important and popular within the last decades. However, there is still inconsistency about the usefulness of sunscreens. Several studies show that inadequate use and incomplete UV spectrum efficacy may compromise protection more than previously expected. The sunscreen market is crowded by numerous products. Inorganic sunscreens such as zinc oxide and titanium oxide have a wide spectral range of activity compared to most of the organic sunscreen products. It is not uncommon for organic sunscreens to cause photocontact allergy, but their cosmetic acceptability is still superior to the one given by inorganic sunscreens. Recently, modern galenic approaches such as
\end{abstract}

micronization and encapsulation allow the development of high-quality inorganic sunscreens. The potential systemic toxicity of organic sunscreens has lately primarily been discussed controversially in public, and several studies show contradictory results. Although a matter of debate, at present the sun protection factor (SPF) is the most reliable information for the consumer as a measure of sunscreen filter efficacy. In this context additional tests have been introduced for the evaluation of not only the protective effect against erythema but also protection against UV-induced immunological and mutational effects. Recently, combinations of UV filters with agents active in DNA repair have been introduced in order to improve photoprotection. This article reviews the efficacy of sunscreens in the prevention of epithelial and nonepithelial skin cancer, the effect on immunosuppression and the value of the SPF as well as new developments on the sunscreen market.

Copyright (C) 2005 S. Karger AG, Basel

\section{Introduction}

Ultraviolet radiation reaching the earth's surface contains about 5\% of UVB (290-320 nm) and 95\% of UVA (320-400 $\mathrm{nm}$ ) radiation. This UV load leads to a wide range of acute and chronic types of skin damage. The acute sunburn is mainly caused by the shorter-wavelength UVB fraction, while polymorphous light eruption at large

\section{KARGER \\ Fax +4161306 1234 E-Mail karger@karger.ch} www.karger.com
(C) 2005 S. Karger AG, Basel $1660-5527 / 05 / 0186-0253 \$ 22.00 / 0$

Accessible online at: www.karger.com/spp
Dr. Tanja Maier

Department of Dermatology and Allergology

Ludwig Maximilian University, Frauenlobstrasse 9-11

DE-80337 Munich (Germany)

Tel. +498951606010, Fax +49 895160 6110, E-Mail Tanja.Maier@med.uni-muenchen.de 
is induced by intensive UVA exposure. Chronic skin damage such as photoaging with wrinkling and dry appearance of the skin is due to repeated UVA exposure. Acute and chronic immunosuppression is not only caused by UVB but also UVA exposure. The most important chronic effect of UV irradiation is photocarcinogenesis. Different wavelengths cause different kinds of DNA lesions. UVB radiation induces the formation of thymidine dimers, the typical UV signature mutation. UVA light causes indirect oxidative stress on DNA base structures with the formation of reactive oxygen species. The efficacy of photoprotection in sunscreens primarily is calculated based on the prevention of erythema, mainly induced by UVB radiation. Yet it is still a matter of debate whether sunscreens can prevent harmful photoinduced effects other than sunburn and how this could be determined quantitatively.

\section{Organic Sunscreens}

The principle of photoprotection in organic sunscreens is the absorption of UV irradiation. In general, their chemical structure consists of aromatic compounds and two functional groups acting as 'electron releasers' and 'electron acceptors'. Upon UV irradiation, the molecule tends to delocalize the electrons to reach a higher state of energy. The excitation caused by absorption of UV light is the favored state of the molecule (fig. 1). The following organic sunscreens belong to the most commonly used groups of sunscreen compounds and present with an absorption maximum within the UVB spectrum (290$320 \mathrm{~nm}$ ): PABA ( $p$-aminobenzoic acid), octocrylene, salicylates, and cinnamates. PABA was introduced as one of the first chemical sunscreens in the 1920s. It had the advantage of being water resistant. However, there was increasing evidence that PABA can elicit photocontact allergies and possibly autoimmune diseases such as systemic lupus erythematosus [1]. Moreover, there were reports that the decomposition of PABA could produce a potentially carcinogenic nitrosamine degradation product [2]. In the 1980s, benzophenone-3 (BZ-3; oxybenzone) became the most frequently used component of sunscreen formulations. Although reactions to PABA or BZ-3 are not representative for organic sunscreens anymore, in general sunscreen products still frequently induce photocontact allergic reactions [3]. In addition, other compounds found in cosmetics for sun protection such as fragrances, preservatives, emulsifiers or solvents have been shown to cause skin irritation, and photoallergic and

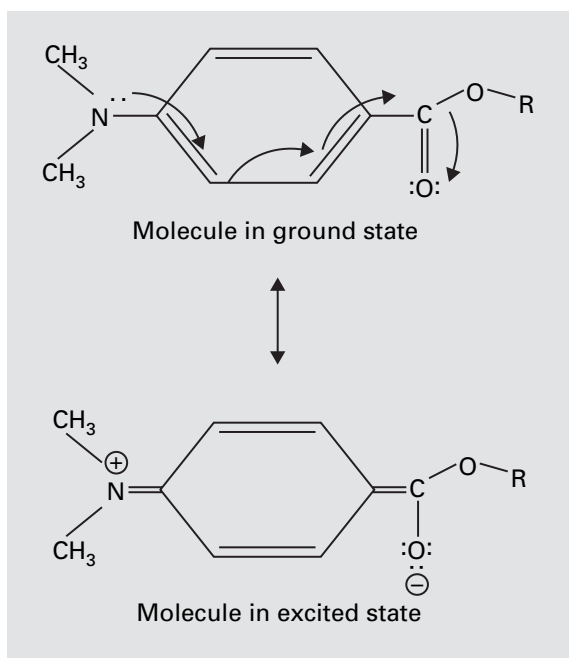

Fig. 1. $P A B A$ molecule: transfer of electrons from the electron-releasing group $\left(=\mathrm{NH}_{2}\right)$ to the electron acceptor group $(=\mathrm{COOH})$ under UV radiation [from 55, with permission].

phototoxic reactions. In contrast to these acute toxic effects of sunscreens, their chronic toxicity has not yet been extensively studied. One important point is the systemic absorption of sunscreens after topical application. It has been shown recently that $0.5 \%$ of the total amount of BZ-3, which was applied topically onto the skin, could be detected in the urine of human volunteers for up to $48 \mathrm{~h}$ [4]. In experiments with rats, BZ-3 has been detected in the liver, kidneys, spleen, heart, muscle and testes [5]. Sunscreens, including BZ-3, have also been found in human breast milk [6]. It is still unknown whether and in which way the route and frequency of topical application, the individual capability of conjugation for the excretion of byproducts (e.g. in children) and the UV-induced conversion of the parent substance into byproducts influence the systemic absorption and chronic toxicity of common sunscreens. In addition, the public demand for water-resistant sunscreens encourages the production of more lipophilic substances, which could influence, i.e. increase, their dermal absorption. Another point recently studied is the postulated in vivo estrogenicity of UV screens [7]. Six frequently used UVA and UVB sunscreens, including BZ-3, were administered orally (median effective dose $1,000-1,500 \mathrm{mg} / \mathrm{kg} / \mathrm{day}$ ) to rats over a period of 4 days. A significant increase of the uterine weight was induced by 3 out of the 6 sunscreens. It was, therefore, hypothesized that the oral intake of sunscreens might be a poten- 
Table 1. A selection of sunscreen materials permitted for use in Europe

\begin{tabular}{|c|c|c|}
\hline & & $\begin{array}{l}\text { Radiation } \\
\text { affected }\end{array}$ \\
\hline$p$-Aminobenzoic acid and its esters & ethylhexyl dimethyl PABA & UVB \\
\hline \multirow[t]{3}{*}{ Salicylates } & ethylhexyl salicylate & UVB \\
\hline & ethyl triazone & UVB \\
\hline & homosalate & UVB \\
\hline \multirow[t]{2}{*}{ Cinnamates } & ethylhexyl methoxycinnamate & UVB \\
\hline & octocrylene & UVB \\
\hline Benzophenones & $\mathrm{BZ}-3$ & UVB/UVA \\
\hline Dibenzoylmethanes & butyl methoxydibenzoylmethane & UVA \\
\hline \multirow[t]{2}{*}{ Camphor derivatives } & 3-benzylidene camphor & UVB \\
\hline & 4-methylbenzylidene camphor & UVB \\
\hline \multirow[t]{3}{*}{ Phenols } & bis-ethylhexyloxyphenol methoxy- & \\
\hline & phenyl triazine & UVB/UVA \\
\hline & drometrizole trisiloxane & UVA \\
\hline Microfine metallic oxides & titanium dioxide & UVB \\
\hline
\end{tabular}

tial risk for humans via bioaccumulation. But also dermal application could induce a significant increase in the uterotrophic testing. This report caused a broad public discussion on the safety of sunscreens, some European countries even banned the suspected products from the market for a short time. Concerning this, the European Union (EU) cosmetics advisory committee stated that there are no estrogenic effects of organic sunscreen products allowed in the EU market. Even the estrogenicity of UV screens is an interesting aspect worth studying; the clinical relevance of these findings is low because at present the benefit using sunscreens outweighs the risks of possible estrogenicity. Recent studies examined the interference of two UV filters, 4-methylbenzylidene camphor and 3-benzylidene camphor with the thyroid and sex hormone system during frog metamorphosis. The results showed no negative effects of these UV filters on the sex ratio and thyroid system of frogs at environmental concentrations [8]. Sunscreens absorbing the longer UVA range have been introduced late in the 1990s, when the contribution of UVA to photoaging and photocarcinogenesis became apparent. Frequently used UVA sunblockers are among others: butyl methoxydibenzoylmethane (e.g. Parsol 1789 ${ }^{\circledR}$, Eusolex 9020 ${ }^{\circledR}$ ), drometrizole trisiloxane (e.g. Mexoryl $\mathrm{XL}^{\circledR}$ ) and terephthalidene dicamphor sulfonic acid (e.g. Mexoryl SX ${ }^{\circledR}$ ). Micronized organic pigments such as methylene bis-benzotriazolyl tetramethylbutylphenol (Tinosorb $\mathrm{M}^{\circledR}$ ), for example, have been introduced as a new conceptual approach to broadspectrum protection. Currently, nanoparticles are used as delivery systems of labile organic sunscreens for the pre- vention of photodegradation (fig. 3). An overview of some UV filters permitted in Europe is given in table 1.

The latest development is represented by UV absorbers entrapped in sol-gel glass microcapsules [9]. The active UV filter is encapsulated within a silica shell of about $1 \mu \mathrm{m}$ in diameter. The potential advantages of these advanced sunscreens are the reduction of the penetration of the UV filter, improved photostability with a lowered allergy potential and avoidance of ingredient incompatibilities.

\section{Inorganic Sunscreens}

Common agents for inorganic sunscreens are zinc oxide $(\mathrm{ZnO})$, titanium oxide $\left(\mathrm{TiO}_{2}\right)$, silicates and ferrum oxide. Disadvantages of these inorganic sunscreens are their visual appearance because of the solid consistency and white pigmentation residue on the skin. Within the last decades galenic preparations of improved quality became available. The particles of solid inorganic sunscreens such as zinc oxide and titanium dioxide were micronized, thus reducing the reflection of visible light and giving them a more transparent appearance and allowing a smoother way of application [10]. The micronization of the particles transforms the inorganic substances into reflectors and absorbants at the same time. Electrons of the metallic oxides are mobilized by absorption of UV radiation, thus forming either free radicals or reactive oxygen species while reducing $\mathrm{O}_{2}$. Interestingly, it has been reported that the photocatalytic activity of $\mathrm{TiO}_{2}$ may alter 


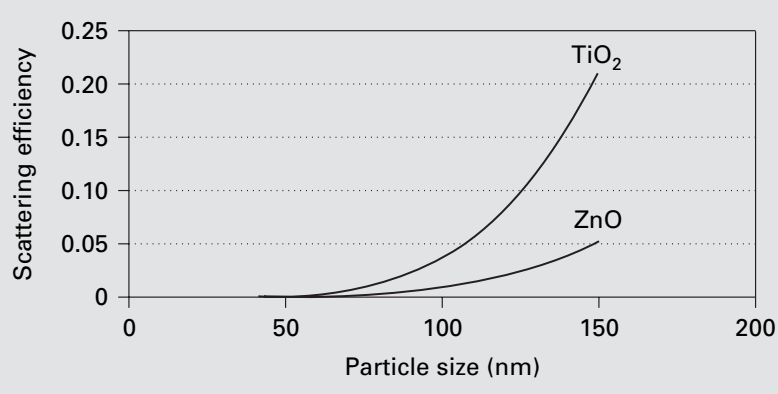

Fig. 2. The white appearance of physical sunscreens is due to their high scattering efficiency of visible light. The scattering efficiency for microfine titanium dioxide is stronger than that with microfine zinc oxide depending on the particle size [from 17, with permission].

cellular homoeostasis and damage cellular RNA and DNA [11]. In cosmetic preparations $\mathrm{TiO}_{2}$ is coated to reduce photocatalytic activity. Recent studies verify a sufficient stability of coated titanium microparticles used in sunscreens with regard to penetration and mechanical abrasion simulating in-use conditions of sunscreens [12]. In view of toxic effects of $\mathrm{TiO}_{2}$ to cellular components, one has to say that on the one hand it does not penetrate the stratum corneum in viable skin. This has been confirmed by Schulz et al. [13], who investigated the dermal absorption of $\mathrm{TiO}_{2}$ by optical and electron microscopy and did not detect microfine $\mathrm{TiO}_{2}$ in deeper stratum corneum layers or epidermis. On the other hand, it has been reported earlier that topical zinc ions traverse skin and can be found in dermis and blood [14]. Topical application of zinc ions protected the skin from UVA and UVB sunburn cell formation [15], by acting as free radical scavengers and antioxidants. Investigations on engineered human skin could demonstrate the significant reduction of molecular photodamage after application of a sun protection factor (SPF) 28 physical sunscreen under simulated sunlight exposure [16]. Comparing the two inorganic particulates currently used in sunscreens, microfine zinc oxide and microfine $\mathrm{TiO}_{2}$, Pinnell et al. [17] could show that microfine $\mathrm{ZnO}$ is more efficient in the absorption of $\mathrm{UV}$ light, especially in the long-wave UVA spectrum, is nonphotoreactive and has a more esthetic appearance than microfine $\mathrm{TiO}_{2}$ because of its lower reflectance of visible light in this particular calculated setting (fig. 2). Nevertheless, the comparison depends on the particle size of the substances, the bigger a $\mathrm{TiO}_{2}$ particle the more UVA protection is achieved. $\mathrm{ZnO}$ is currently used in sunscreens but not permitted as a UV filter in Europe. The advantages of anorganic micronized reflecting powders, in general, are their stability, the broad-spectrum protection, the lack of photosensitization and their low toxicity compared to chemical UV filters.

\section{SPF, Immune Protection Factor, Mutation Protection Factor?}

The SPF is a quantitative, established measure of the effectiveness of a sunscreen formulation. This factor is determined by assessing individual sensitivity to sunburn by solar-stimulated radiation with or without sunscreen. The SPF is defined as follows: SPF = minimal erythemal dose in sunscreen-protected skin divided by minimal erythemal dose in non-sunscreen-protected skin.

In the United States sunscreens belong to the group of over-the-counter drugs and are supervised by the Food and Drug Administration (FDA). Guidelines for standardized sunscreen evaluation have been proposed by the FDA. They include the number of tested subjects, skin type, site of testing, light source, and mode of application [18]. In the European countries SPF testing has been standardized by the European Cosmetic Toiletry and Perfumery Association in 1994 [19]. In table 1 a selection of UV filters permitted for use in Europe are listed. In 2000 the COLIPA standardized SPF test method was used as a basis for the development of a harmonized international test method between European, American, Japanese and South African working groups. It has to be stressed that the SPF, as defined, measures the sunscreen protection against erythema. Solar UV radiation (290-400 nm) reaching the earth surface contains no more than 5-10\% UVB (290-320 nm) and 90-95\% of UVA (320-400 nm). UVB is responsible for $80-90 \%$ of the sunburn. In this respect, the SPF measuring erythema induction is a factor measuring mainly the UVB protection of a sunscreen formulation.

Different methods for testing the UVA protection factor have been investigated, but so far no methodology for measuring the biological effect of UVA on the skin like UVA-induced photoaging comparable with the UVB erythema test could be defined. In particular, the following in vivo techniques for UVA protection measurement are used: the persistent pigment darkening and the immediate pigment darkening method. With respect to in vitro methods the Australian standard testing is the only method officially accepted in Australia to measure UVA protection. Other methods are quantifying the UVA protec- 
tion factor in relation to the SPF, e.g. the Boots rating system [20]. International working groups have been developing a standardized measurement for UVA protection. Currently, a new in vitro method measuring the relative UVA protection of different sun care products, the so-called UVA balance, has been tested and will be transferred into a DIN method soon [21].

Within the last years, problems of the SPF became obvious. The reliability of SPF and corresponding testing methods were questioned. The SPF is a ratio based on a standardized but nevertheless individual test referring to a group of about 10-20 individuals with different skin types. Although it was demonstrated recently that SPF testing is accurate and reproducible under standardized conditions [22], the definite SPF in reality depends on the individuals' habits and state of health. For example, the applied dose in lab testing is standardized with $2 \mathrm{mg} / \mathrm{cm}^{2}$. Observations in independent consumer groups showed that the amount of sunscreen applied was $0.5-1 \mathrm{mg} / \mathrm{cm}^{2}$, thus reducing the labelled SPF [23]. Although the laboratory SPF takes photodegradation into account by measuring the end point after irradiation, laboratory tests do not include the possible diminution of SPF by environmental factors and the effects of photodegradation after longterm and repeated sun exposure. The SPF is also dependent on the light source and wavelength used. Commercial SPF testing is routinely performed with UV sources which contain a lower level of UVA compared to the UVA in natural sunlight. Sunscreens are believed to reduce long-term effects of solar exposure such as photoaging and skin cancer, but the question is whether erythema induction as measured by the SPF is a good enough indicator for UV damage such as immunosuppression, DNA damage, clinically overt photoaging, mutations and tumor formation.

In this respect, the following terms have been introduced: immune protection factor and mutation protection factor [24]. The immune protection factor analogous to SPF defines the ability of a sunscreen to protect against immune suppression and can be calculated by comparing minimal immunosuppressive doses with sunscreen-protected versus nonprotected test subjects.

The problem in testing the immune protection factor is that the method is not standardized yet and depends on the immunological test used. The contact hypersensitivity and delayed type hypersensitivity methods are two in vivo test modalities used to study immunosuppression. In contact hypersensitivity a hapten is applied directly to UV-irradiated skin and the degree of patch test erythema is measured by a reflectance spectrometer in humans. For
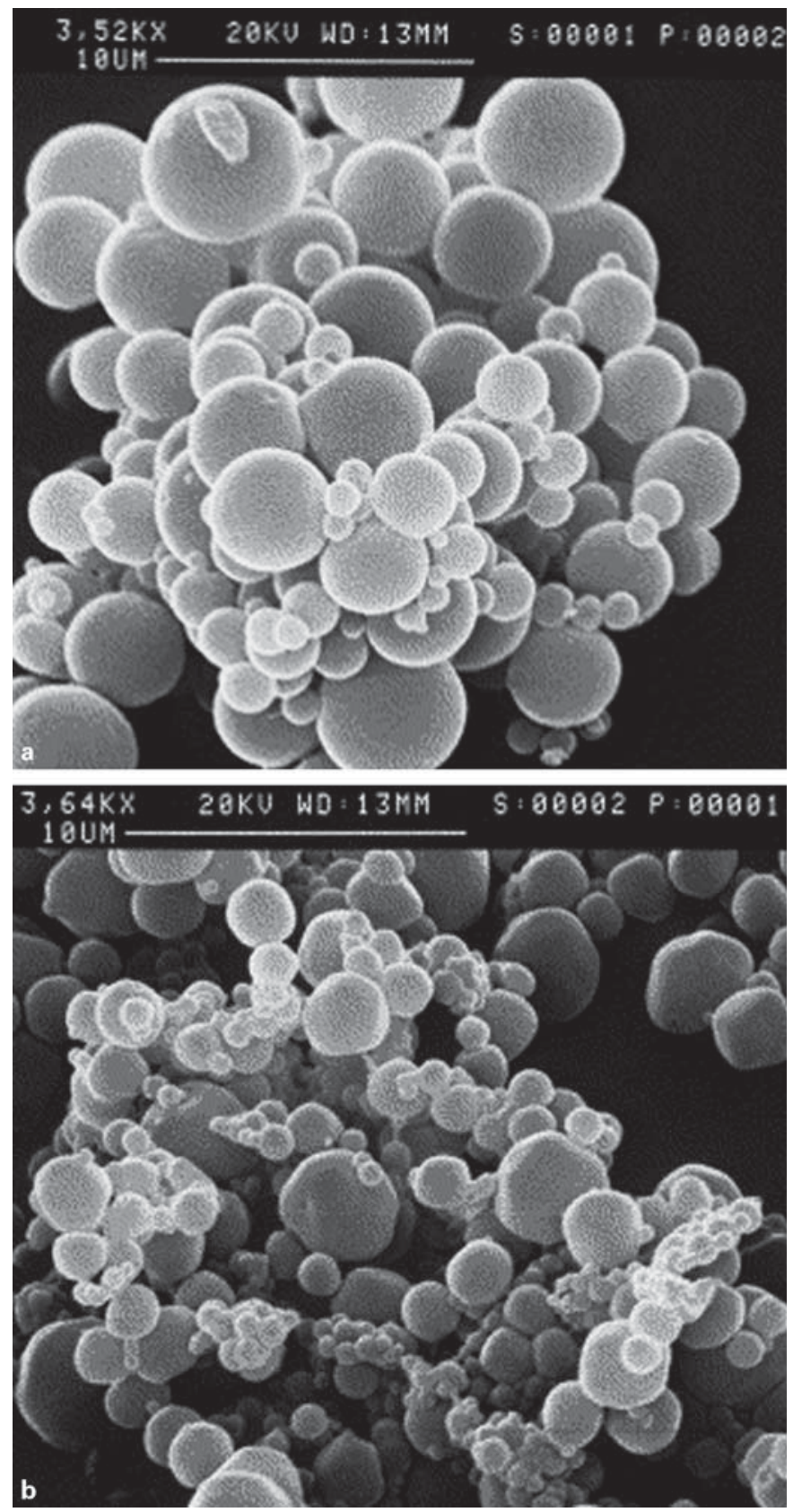

Fig. 3. a, b Production of PLGA (poly- $D, L$-lactide-co-glycolide; a biocompatible polymer) nanoparticles as vehicles for sunscreen agents for the prevention of photodegradation of the sunscreen [from 12, with permission].

delayed type hypersensitivity, recall antigens are applied subcutaneously and the UV-induced suppression of the elicitation phase of an existing cell-mediated immune response is documented. Another concept for measuring the nonerythema effects of UV radiation is the mutation 
protection factor. The mutation protection factor is defined as the ability of a sunscreen to inhibit p 53 mutations for example as induced by UVB irradiation [25]. The number of p53 mutations can be measured by allele-specific polymerase chain reaction and immunohistochemical staining detecting mutated p53 protein. Standardized techniques of calculating the mutation protection factor and the immune protection factor still have to be developed in the future.

Concerning UVA-induced photodamage a new concept has been introduced recently. Photoaging studies with UVA recognized the direct interaction of the longerwavelength UVA with dermal fibroblasts. It has been found that mutations of mitochondrial DNA in dermal fibroblasts play a critical role in UVA-induced photoaging [26]. The detection of these UVA-induced deletions in mitochondrial DNA can be used to measure the protective effect of sunscreens against photoaging of human skin.

\section{SPF 30 or Higher?}

The current sunscreen market is characterized by a wide range of different products of varying SPFs ranging from less than 5 to 60 . Within the last years, there was a tendency towards the higher SPF sunscreens of SPF 30 and more. Recently, a SPF of 30 was claimed to be sufficient by the FDA. SPF exceeding this level will be labelled as 30 plus. The question remains if there is a need for sunscreens with a SPF higher than 30. A number of facts do speak for a further development and use of high SPF. One fact, which has already been mentioned earlier, is that the application modality differs in testing methods and in consumer habits and the applied dose of sunscreens does not exceed $1 \mathrm{mg} / \mathrm{cm}^{2}$ in reality. This is half of the standardized testing amount of $2 \mathrm{mg} / \mathrm{cm}^{2}$. In this way, the application of high SPF sunscreens may still reach a higher sun protection despite a wrong application technique than a low SPF sunscreen. Another point of discussion is that in commercial sunscreen testing facilities, subjects of the Fitzpatrick skin type 1 and 2 are preferred, because of their quick erythema induction under UV light. Interestingly, in persons of higher skin types the SPF decreases [27]. In this way, the labelled SPF will be lower than labelled in the normal population with different skin types. This clearly speaks for the use of higher SPF sunscreens. Additionally, it has already been mentioned that although testing UV sources reflect standardized FDA and COLIPA guidelines, they still do not nec-

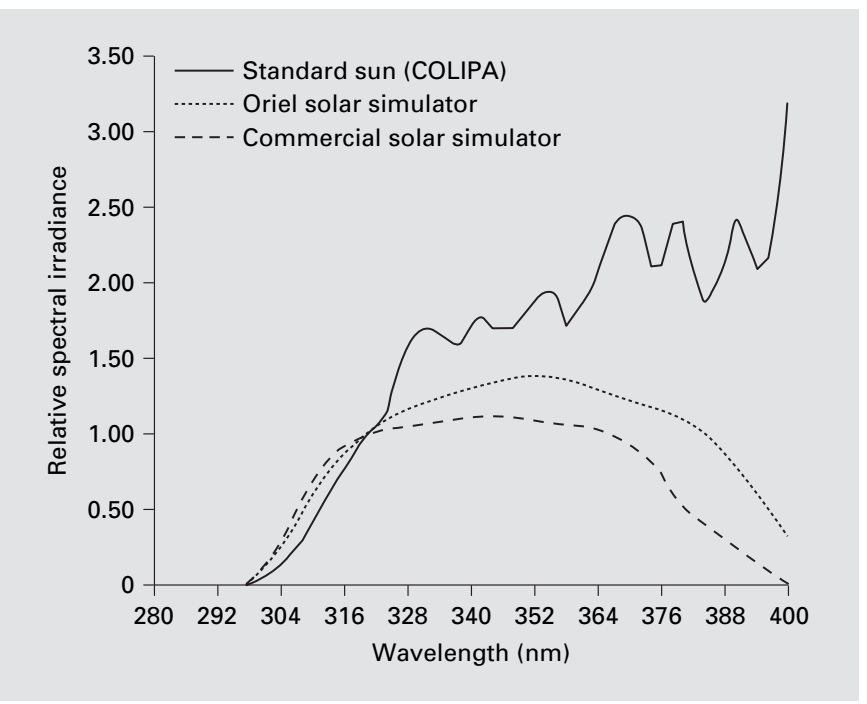

Fig. 4. Comparison of spectral irradiances of natural sunlight, Oriel $1000 \mathrm{~W}$ solar simulator and a commonly used commercial solar simulator: the two UV sources have similar UVB (290-320 nm) irradiances, but less UVA $(340-400 \mathrm{~nm})$ production than natural sunlight [from 56, with permission].

essarily need a UVA fraction as high as found in natural UV light (fig. 4). As UVA light does also induce erythema a UVA-reduced source will produce a higher SPF [28]. In animal models, it has been shown that already suberythemal doses are sufficient to induce photocarcinogenesis with DNA damage and immune suppression. In this respect, high SPF sunscreens could possibly offer a better protection against suberythemal UV damage than lower SPF sunscreens.

Concomitant factors responsible for the reduction of the labelled SPF are daily in-use conditions such as sweating, rubbing, abrasion, water immersion and photodegradation of the products, for example. A main indication for the development of high SPF sunscreens anyhow remains with respect to the protection of high-risk patients with photosensitive disorders such as lupus erythematosus or porphyria. It could be shown that preparations containing the extremely high formulation of $50 \% \mathrm{TiO}_{2}$ were more sufficient in reducing light transmission and in cell protection of photosensitized skin compared to usual sunscreens [29]. Interestingly, photosensitized patients very often feel no sufficient benefit from sunscreen use. Studies could show that not only the wrong application technique [30] as mentioned before but also the use of common narrow-band sunscreens is one reason for inadequate protection in this population. As most photosen- 
sitivity disorders are caused by UVA, only broad-spectrum sunscreens can offer ideal protection.

To summarize, despite its limitations discussed above the SPF is the most reliable key information for the consumer of sun care products at present.

\section{Photocarcinogenesis}

\section{Sunscreens and Nonmelanoma Skin Cancer}

The influence of sunscreen use on the incidence of epithelial tumors has been documented in several human epidemiological studies. It has been shown that repeated application of sunscreen can moderately, yet significantly reduce the development of precursor lesions such as solar keratoses in comparison to placebo use [31]. Naylor et al. [32], moreover, demonstrated in a controlled trial with a 2-year follow-up that regular use of a sunscreen can significantly reduce cutaneous carcinoma by suppression of precancerous lesions. Darlington et al. [33] could show a significant reduction of solar keratoses in sunscreen users, while a $\beta$-carotene supplementation performed perorally had no influence on the occurrence of actinic keratoses. A large randomized trial with a 4.5 -year follow-up phase by Green et al. [34] showed the preventive effect of consistent sunscreen use by adults on the incidence of squamous cell carcinoma. Additionally, a study from 1986 demonstrated the protective effect of sunscreen in childhood as regards nonmelanoma skin cancer [35]. Despite these corresponding data, there exists a group of reports showing exactly the opposite. Kricker et al. [36], for example, observed an elevated incidence of basal cell carcinoma in sunscreen users. Perhaps the latter type of tumor must be considered separately from the other frequent type of nonmelanoma skin cancer.

\section{Sunscreens and Melanoma}

Several studies have demonstrated the protective effects of sunscreen use in precancerous and cancerous skin lesions. However, the preventive effect of photoprotection on melanoma is still a matter of discussion. A variety of studies have shown conflicting results. Recently, an epidemiological study performed by Autier et al. [37] presented an increase in the melanoma incidence with repeated use of sunscreen. This finding is supported by an observed increase of the number of nevi in European children despite sunscreen use. In contrast to that, Gallagher et al. [38] documented a reduced number of nevi in fairskinned children under sunscreen-induced photoprotection. It still remains unclear which wavelength is respon-

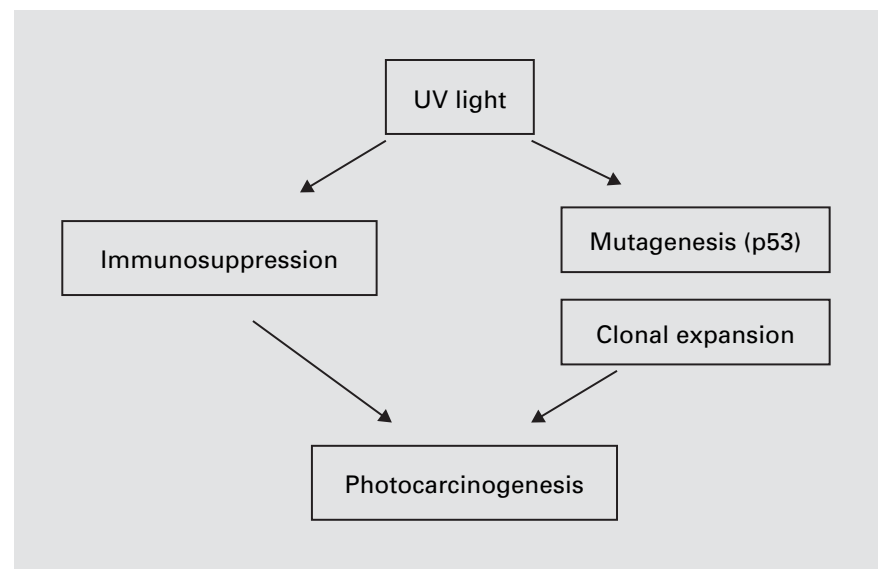

Fig. 5. Proposed model of photocarcinogenesis.

sible for melanoma induction. UVB is known to cause direct DNA damage with the formation of thymidine dimers (mostly C-T transversions, called UV signature mutation). A defective nucleotide excision repair system, for example the UVB mutation of the p53 suppressor gene, could contribute to the development of neoplasia such as melanoma. The more indirect UVA-induced oxidative DNA damage could play a crucial role in the initiation of melanoma. Additionally, the UV-induced suppression of immunity would allow p53-mutated cells to proliferate and expand. Within recent years, the contribution of UVA-induced immune suppression to photocarcinogenesis through an oxidative pathway became a point of interest. So far, it has to be stated that UVA radiation acts as a tumor promotor, but not initiator. Similar to UVB, UVA is capable to induce specific mutations in oncogenes (mostly T-G transitions in the p53 gene), but the effects are less dramatic than those induced by UVB. As far as it appears today, not only UVB but also UVA could contribute to the development of melanoma [39] (fig. 5). In this respect, the use of broad-spectrum sunscreens seems to be an important issue in the prevention of melanoma induction. Broad-spectrum sunscreens providing high UVA protection have become popular only within the last decade. This might be one reason for the studies reporting an increased melanoma incidence despite sunscreen application. Another point often mentioned is the fact that the higher the SPF, the longer the recreational sun exposure and consecutively the more marked the skindamaging effects. 


\section{New Developments}

The usefulness of sunscreens as discussed above is still not ideal because of the inadequate use, incomplete spectral range of activity and potential toxicity. In this respect, a variety of supplements have been studied recently in order to improve photoprotection. The following substances added to sunscreens failed to increase the protective effect. Dietary $\beta$-carotene known as a free radical scavenger did not improve the effect of sunscreen use on the development of skin cancer in humans $[33,34]$. In animal experiments, $\beta$-carotene could not overcome UVB-induced immunosuppression measured by contact hypersensitivity testing [40].

Another animal model-based trial investigated the protective effect of the chemically induced epidermal melanogenesis with furocoumarin. This epidermal tanning did not protect against photocarcinogenesis in mice [41]. Synthetic suntan induced by self-tanning products containing dihydroxyacetone (DHA) was believed to have no protection against photoinduced skin damage [42]. Recent studies reported on a photoprotective effect of DHA against UVB and the ability to delay photocarcinogenesis in hairless mice [43]. The combination of an insect repellent such as diethylmethylbenzamide (DEET) with sunscreens reduces the SPF of the sunscreens due to its solvent action and is not advisable [44]. Positive effects of reducing photodamage have been observed with plant extracts functioning as antioxidants. The photoaging process and photocarcinogenesis in particular is partly caused by reactive oxygen species. The topical application of plant oligo- or polysaccharides has been shown to have antioxidant effects, e.g., extracts of aloe vera or tamarind applied topically inhibited the UVB-induced immunosuppression and reduced IL-10 production in keratinocytes. Natural flavonoids such as green or black tea polyphenols [45, 46], epigenin [47] and silymarin (milk thistle) reduced UVB-induced erythema, tumorigenesis and immunosuppression in mice [48]. The two antioxidant vitamins $\mathrm{C}$ and $\mathrm{E}$ are promising supplements in sunscreens. Ascorbic acid prevented the secretion of proinflammatory cytokines by UVA, UVB-induced DNA damage and UV-induced immunosuppression in several studies [49]. $\alpha$-Tocopherol reduced UVB-induced erythema, DNA damage and restored immune responses [50]. $\mathrm{N}$-Acetylcysteine is known as another antioxidant and has been investigated with respect to its photoprotective effects. In mice experiments it was capable to repair UVinduced DNA damage in keratinocytes [51]. Another scavenger of free radicals is the hydroxypropyl- $\beta$-cyclo- dextrin (HP- $\beta-C D)$, which has shown its ability to effectively scavenge free radicals produced by the sunscreen agent butyl methoxydibenzoylmethane [52]. A stable trap radical was used for coupling of free radicals which were generated during irradiation of the sunscreen with and without HP- $\beta-C D$. A new topical mechanism is the direct application of DNA repair enzymes after photoinduced DNA damage with dimer formation. The dimer-specific photolyase was encapsulated into liposomes and topically administered immediately after UVB irradiation as recently published by Krutman [53]. UVB radiation-induced dimers were reduced by $40-45 \%$. Accordingly, the dimer repair prevented the UVB-induced immune suppression. In patients with xeroderma pigmentosum the daily application of liposomal DNA repair enzymes for 1 year could diminish the rate of new actinic keratoses and basal cell carcinoma [54]. In contrast to conventional sunscreens, which offer only prophylactic protection, the above-mentioned approaches could restore damage, which has already occurred, thus giving the opportunity of combining protection with repair. Yet the long-term effects or best application mode have not been investigated to the needed extent so far.

\section{Final Remarks}

Evidence is accumulating that various skin cancers and photoaging are not only caused by one type of UV light but by the whole spectrum of sun rays. In this respect sunscreens with UVA protection abilities have recently become the center of interest. Mainly inorganic sunscreens experience a revival as they provide full-spectrum protection and so prevent photocarcinogenesis. The two mainly used inorganic substances $\mathrm{TiO}_{2}$ and $\mathrm{ZnO}$ offer excellent UV protection and due to the modern cosmetic formulations such as the nanoparticle encapsulation of sunscreens, their cosmetic appearance has much improved. The main advantage of inorganic sunscreens versus organic screens is their low allergenic potential. Organic sunscreens are known to induce allergic contact dermatitis and photoallergic dermatitis. Although the UVA protection factor is often not defined exactly, an adequate photoprotection can only be achieved with broad-spectrum sunscreens, including UVA. High SPF should be preferred, as the common in-use conditions reduce the labelled SPF. In view of recently discussed systemic effects of sunscreens, it seems advisable to use inorganic sunscreens particularly in children or to prevent absorption by entrapment with glass capsules. Nevertheless, for 
full photoprotection sunscreens should be combined with other protection methods such as reduction of sun exposure, avoidance of sun, protection clothes and sun glasses.
In conclusion, despite controversial results concerning the beneficial effects of sunscreens and their efficacy in the prevention of skin neoplasias, including melanoma, regular use of sunscreens should be recommended.

\section{References}

1 Mackie B, Mackie L: The PABA story. Australas J Dermatol 1999;40:51-53.

2 Loeppky R, Hastings R, Sandbothe J, Heller D, Bao Y, Nagel D: Nitrosation of tertiary aromatic amines related to sunscreen ingredients. IRAC Sci Publ 1991;105:244-252.

3 Schauder S, Ippen H: Contact and photocontact sensitivity to sunscreens. Contact Dermatitis 1997;37:221-232.

4 Gustavsson Gonzalez H, Farbrot A, Larkö O: Percutaneous absorption of benzophenone-3, a common component of topical sunscreens. Clin Exp Dermatol 2002;27:691-694.

5 Okereke CS, Barat SA, Abdel-Rahman MS: Safety evaluation of benzophenone-3 after dermal administration in rats. Toxicol Lett 1995: 80:61-67.

6 Hany J, Nagel R: Nachweis von UV-Filtersubstanzen in Muttermilch. Dtsch LebensmittelRundschau 1995;91:341-345.

7 Schlumpf M, Cotton B, Conscience M, Haller $\mathrm{V}$, Steinmann B, Lichtensteiger W: In vitro and in vivo estrogenicity of UV screens. Environ Health Perspect 2001;109:239-244.

8 Kunz PY, Galicia HF, Fent K: Assessment of hormonal activity of UV filters in tadpoles of frog Xenopus laevis at environmental concentrations. Mar Environ Res 2004;58:431-435.

9 Lapidot N, Gans O, Biagini F, Sosonkin L, Rottman C: Advanced sunscreens: UV absorbers encapsulated in sol-gel glass microcapsules. J Sol-Gel Sci Technol 2003;26:67-72.

10 Mitchnik M, Fairhurst D, Pinnell S: Microfine zinc oxide as a photostable UVA/UVB sunblock agent. J Am Acad Dermatol 1999;40: 85-90.

11 Wamer W, Yin J, Wei R: Oxidative damage to nucleic acids photosensitized by titanium dioxide. Free Radic Biol Med 1997;23:851858.

12 Perugini P, Simeoni S, Scalia S, Genta I, Modena T, Conti B, Pavanetto F: Effect of nanoparticle encapsulation on the photostability of the sunscreen agent, 2-ethylhexyl-p-methoxycinnamate. Int J Pharm 2002;246:37-45.

13 Schulz J, Hohenberg H, Pflücker F, Gärtner E, Will T, Pfeiffer S, Wepf R, Wendel V, GersBarlag H, Wittern KP: Distribution of sunscreens on skin. Adv Drug Deliv Rev 2002; 54(suppl 1):157-163

14 Hallmans G, Liden S: Penetration of $65 \mathrm{Zn}$ through the skin of rats. Acta Derm Venereol 1979;59:105-112.
15 Record IR, Jannes M, Dreosti IE: Protection by zinc against UVA- and UVB-induced cellular and genomic damage in vivo and in vitro. Biol Trace Elem Res 1996;53:19-25.

16 Rouabia M, Mitchell DL, Rhainds M, Claveau $\mathrm{J}$, Drouin R: A physical sunscreen protects engineered human skin against artificial solar ultraviolet radiation-induced tissue and DNA damage. Photochem Photobiol Sci 2002; 1: 471-477.

17 Pinnell SR, Fairhurst D, Gillies R, Mitchnick MA, Kollias N: Microfine zinc oxide is a superior sunscreen ingredient to microfine titanium dioxide. Dermatol Surg 2000;26:309-314.

18 US FDA: Sunscreen drug products for overthe-counter human drugs; proposed safety, effectiveness and labelling conditions, Federal Register, 1978, pp 38206-38269.

19 COLIPA, European Cosmetic, Toiletry and Perfumery Association: COLIPA Sun Protection Factor Test Method. 94/289 Brussels 1994.

20 Schrader K: Die Sonnenschutzfaktorbestimmung. Bundesgesundheitsbl Gesundheitsforsch Gesundheitsschutz 2001;44:457-462.

21 Gers-Balag H, Klette E, Springob C, Finkel P, Rudolph T, Gonzenbach HU, Schneider P, Kockott D, Heinrich U, Tronnier H, Bernklau R, Johncock W, Langner R, Driller H, Westenfelder H: In vitro testing to assess the UVA protection performance of sun care products. Int J Cosmet Sci 2001;23:3-14.

22 Poh Agin P, Edmonds SH: Testing high SPF sunscreens: a demonstration of the accuracy and reproducibility of the results of testing high SPF formulations by two methods and at different testing sites. Photodermatol Photoimmunol Photomed 2002;18:169-174.

23 Wulf HC, Stender IM, Lock-Anderson J: Sunscreens used at the beach do not protect against erythema: a new definition of SPF is proposed. Photodermatol Photoimmunol Photomed 1997;13:129-132.

24 Gil EM, Kim TH: UV-induced immune suppression and sunscreen. Photodermatol Photoimmunol Photomed 2000;16:101-110.

25 Ananthaswamy HN, Loughlin SM, Ullrich SE, Kripke ML: Inhibition of UV-induced p53 mutations by sunscreens: implications for skin cancer prevention. J Invest Dermatol Symp Proc 1998;3:52-56.

26 Berneburg M, Grether-Beck S, Kürten V, Ruzicka T, Briviba K, Sies H, Krutman J: Singlet oxygen mediates the UVA-induced generation of the photoaging-associated mitochondrial common deletion. J Biol Chem 1999;274. 15345-15349.
27 Damian DL, Halliday GM, Barnetson RSC: Sun protection factor measurement of sunscreens is dependent on minimal erythema dose. Br J Dermatol 1999; 141:502-507.

28 Sayre RM, Stanfield J, Bush AJ, Lott DL: Sunscreen standards tested with differently filtered solar stimulators. Photodermatol Photoimmunol Photomed 2001;17:2782-2783.

29 Schwarz VA, Klein SD, Hornung R, Knochenmuss R, Wyss P, Fink D, Haller U, Walt H: Skin protection for photosensitized patients. Lasers Surg Med 2001;29:252-259.

30 Azurdia RM, Pagliaro JA, Rhodes LE: Sunscreen application technique in photosensitive patients: a quantitative assessment of the effect of education. Photodermatol Photoimmunol Photomed 2000;16:53-56.

31 Thompson SC, Jolley D, Marks R: Reduction of solar keratoses by regular sunscreen use. $\mathrm{N}$ Engl J Med 1993;329:1147-1151.

32 Naylor MF, Boyd A, Smith DW, Cameron GS, Hubard D, Neldner KH: High SPF sunscreens in the suppression of actinic neoplasia. Arch Dermatol 1995;131:170-175.

33 Darlington S, Williams G, Neale R, Frost C, Green A: A randomized controlled trial to assess sunscreen application and beta carotene supplementation in the prevention of solar keratoses. Arch Dermatol 2003;139:451-455.

34 Green A, Williams G, Neale R, Hart V, Leslie D, Parsons P, Marks GC, Gaffney P, Battistutta D, Frost C, Lang C, Russell A: Daily sunscreen application and betacarotene supplementation in prevention of basal cell and squamous cell carcinoma of the skin: a randomized controlled trial. Lancet 1999;354: 723-729.

35 Stern RS, Weinstein MC, Baker SG: Risk reduction for non-melanoma skin cancer with childhood sunscreen use. Arch Dermatol 1986; 122:537-545.

36 Kricker A, Armstrong BK, English DR, Heenan PJ: Does intermittent sun exposure cause basal cell carcinoma? A case-control study in Western Australia. Int J Cancer 1995;60:489_ 494.

37 Autier P, Dore JF, Cattaruzza MS, Renard F, Luther H, Gentiloni-Silverej F, Zantedeschi E, Mezzetti M, Monjaud I, Andry M, Osborn JF, Grivegnee AR: Sunscreen use, wearing clothes and number of nevi in 6- to 7-year-old European children. J Natl Cancer Inst 1998;90: 1873-1880. 
38 Gallagher RP, Rivers JK, Lee TK, Bajdik CD, Mc Lean DI, Coldman AJ: Broad-spectrum sunscreen use and the development of new nevi in white children: a randomized controlled trial. JAMA 2000;283:2955-2960.

39 Rünger TM: Role of UVA in the pathogenesis of melanoma and non-melanoma skin cancer. Photodermatol Photoimmunol Photomed 1999;15:212-216.

40 Noonan FP, Webber LJ, De Fabo EC, Hoffmann HA, Bendich A, Mathews-Roth M: Dietary beta-carotene and ultraviolet-induced immunosuppression. Clin Exp Immunol 1996; 103:54-60.

41 Kipp C, Lewis EJ, Young AR: Furocoumarininduced epidermal melanogenesis does not protect against skin photocarcinogenesis in hairless mice. Photochem Photobiol 1998;67: 126-132.

42 Levy SB: Dihydroxyacetone-containing selftanning lotions. J Am Acad Dermatol 1992;27: 989-993.

43 Petersen AB, Na R, Wulf HC: Sunless skin tanning with dihydroxyacetone delays broadspectrum ultraviolet photocarcinogenesis in hairless mice. Mutat Res 2003;542:129-138.
44 Montemarano AD, Gupta RK, Burge JR, Klein K: Insect repellent and efficacy of sunscreens. Lancet 1997;349:1670-1671.

45 Wang ZY, Huang MT, Ferraro T, Wong CQ, Lou YR, Reuhl K, Iatropoulos M, Yang CS, Conney AH: Inhibitory effect of green tea in the drinking water on tumorigenesis by ultraviolet light and 12-o-tetradecanoylphorbol-13acetate in the skin of skh-1 mice. Cancer Res 1992;52:1162-1170.

46 Zhao J, Jin X, Yaping E, Zheng ZS, Zhang YJ, Athar M, DeLeo VA, Mukhtar H, Bickers DR, Wang ZY: Photoprotective effect of black tea extracts against UVB-induced phototoxicity in skin. Photochem Photobiol 1999;70:637_ 644.

47 Birt DF, Mitchell D, Gold B, Pour P, Pinch $\mathrm{HC}$ : Inhibition of ultraviolet light induced skin carcinogenesis in SKH-1 mice by apigenin, a plant flavonoid. Anticancer Res 1997;17:8592.

48 Katiyar SK: Treatment of silymarin, a plant flavonoid, prevents ultraviolet light-induced immune suppression and oxidative stress in mouse skin. Int J Oncol 2002;21:1213-1222.

49 Tebbe B, Wu S, Geilen CC, Eberle J, Kodelja V, Orfanos CE: $L$-Ascorbic acid inhibits UVAinduced lipid peroxidation and secretion of IL1 alpha and IL-6 in cultured human keratinocytes in vitro. J Invest Dermatol 1997;108: 302-306.
50 Mc Vean M, Liebler DC: Inhibition of UVB induced DNA photodamage in mouse epidermis by topically applied alpha-tocopherol. Carcinogenesis 1997; 18:1617-1622.

51 Bush JA, Ho VC, Mitchell DL, Tron VA, Li G: Effect of $\mathrm{N}$-acetylcysteine on UVB-induced apoptosis and DNA repair in human and mouse keratinocytes. Photochem Photobiol 1999; 70:329-333.

52 Scalia S, Simeoni S, Barbieri A, Sostero S: Influence of hydroxypropyl-beta-cyclodextrin on photo-induced free radical production by the sunscreen agent, butyl-methoxydibenzoylmethane. J Pharm Pharmacol 2002;54:15531558.

53 Krutman J: New developments in photoprotection of human skin. Skin Pharmacol Appl Skin Physiol 2001;14:401-407.

54 Yarosh D, Klein J, O’Connor A, Hawk J, Rafal E, Wolf P: Effect of topically applied T4 endonuclease $\mathrm{V}$ in liposomes on skin cancer in xeroderma pigmentosum: a randomised study. Xeroderma Pigmentosum Study Group. Lancet 2001;357:926-929.

55 Wolf R, Wolf D, Morganti P, Ruocco V: Sunscreens. Clin Dermatol 2001;19:452-459.

56 Poon TS, Barnetson RS: The importance of using broad spectrum SPF $30+$ sunscreens in tropical and subtropical climates. Photodermatol Photoimmunol Photomed 2002;18/4: $175-178$ 